\title{
Important B2C Aspects of Location Based Marketing
}

\author{
PhD candidate Mohammad M. Hazimeh \\ University of Economics - Varna, Varna, Bulgaria \\ mohamadmhazimeh@outlook.com
}

\begin{abstract}
Location Based Marketing is the act of the organization getting their business in front of their customer. This act aims to attract customers at the moment when they are most interested in purchasing from the business. This process requires a two way interaction where the business reaches out for the customer and the customer is grasped by the action and therefore responds to the marketing technique being targeted by. A customer may be targeted remotely where they would be far off, or maybe within the targeted area geotargeted by the business's location based marketing tactics. Location Based Marketing is shaping up now a day marketing techniques where it has even become much of a necessity in the year 2020 due to the ongoing Covid-19 Pandemic.
\end{abstract}

Keywords: Marketing, Location, Location Based Marketing, business, customers, targeting, geotargeting.

JEL Code: $M 31$

DOI: https://doi.org/10.36997/IJUSV-ESS/2020.9.3.48

\section{Introduction}

Ever since location determination has come into being, it has become an aspect in marketing. The usage of location in marketing has long been called geomarketing. The main elements in geomarketing or using location within marketing is targeting and segmentation (Hendricks, 2017). Location came into being with the naming of countries, states, cities and towns, streets which were even given their numbers later on, and home numbers as well. The research of location in the field of marketing is not something new, it dates back to the 19th century. (Act On. 2017) .Ever since then, a precise location or destination has been able to be determined, so when you want to reach a person at their home, you get their address; for example a precise address to reach Mr. Elie Khoury would be, Lebanon, Bekaa, Zahle, Saint Charbel Road, street 202, building 74, 3rd floor apartment number 12. Companies and institutions relatively were given precise addresses where they registered in, and are located in. Since that time, the company had to first of all use its own location in its marketing in order to give directions to customers where to reach the company or organization in order to be able reach it, and then to buy their products or services. In the nineteenth century, neighborhoods were classified according to social and economic classes. Marketers and companies would use that information in order to gain access and tend to specific areas and specific markets. This segmentation would set the perfect strategy for targeting. (Act On. 2017) Marketers looked upon location as factor to develop marketing strategies where they head out to reach potential consumers at their own location rather than wait for them to come to the organization or company's own location. (Munoz, 2019) That is where the first form of marketing at the customer's location came into being, or what is now called primitive location based marketing. There is immense marketing value in knowing an audience's location. ( Hendricks, 2017) Before the advancement of technology and the entrance of social media in the world of marketing, companies used to send mail letters as advertisements to consumers at their home, technology has just made things easier by providing instant advertisements reaching the consumers wherever they are at whenever time necessary. (Miller, 2019) Advertisements such as promotional letters began to be delivered to customers' own locations whether it was their homes, offices, or institutions, which was then further developed to where some organizations began creating their own product catalogues and magazines which are updated seasonally and delivered to mailboxes or homes at the consumer's location. Knowing the customer or consumer's location is of great marketing value, hence it helps in determining and reaching the consumer at the right time and place.( Miller, 2019) 


\section{Defining Location Based Marketing}

With the advancement of technology and technological communication, came the advancement of social media and the daily internet usage. These advancements led to having most of the human population being connected to these social media networks and the internet at a twenty four hour basis through the advancement of the mobile phones which are connected to the internet the whole time and hold within them all the applications, networks and sites people use and live through. Choosing the word live through is meant literality hence human being connect to one another all through their days on these sites, networks, and applications, they communicate, express, spend their time, browse, and recently, shop, through their mobile phones. This new high usage of the mobile phones and applications has led to the advancement of marketing where most marketers and advertising agencies, or even companies with marketing departments had to shift their marketing strategies to coordinate with this technological evolution, therefore social media marketing and social media integrated marketing came into being, where it is now a necessity and plays the major role in today's marketing. All companies which have not adapted to this sort of marketing shift are considered late, or are even losing ground in now a days marketing and markets. Social Media marketing is the process of connecting to your customers during they everyday routine. Social media might be easy to use, but marketing on social media or known as social media marketing, has become a study on its own. Social media and search engines are gathering mass information about every single individual using their services throughout personal data, data entered, search engines, and even preferences used by everyday users. This mass data is the main aspect of social media marketing and targeted marketing. One main newly adapted form of marketing according to this gathered data is location based marketing. Location based marketing is a marketing strategy that mainly relies on collected location information data as a main with several other collected data factors at hand from preferences to gender, and many more. This form of marketing enables institutions to target the most potential customers, in specifically those who are within the area or region of the institution which are reachable by the institution or are able to reach it themselves. One example of location based marketing via social networks, is marketing on Facebook, and that by its own has several types, the first type is when paying to boost your post or to publish a public application that would reach out users which are not even following your business page, there has been an option added to reach out to a certain crowd upon a designated area or location which Facebook lets your determine. A second type that Facebook offers for itself is connecting users with events nearby, where the events application on Facebook notifies you of events happening which are located near you. The third and final type of location based marketing Facebook offers is being able to determine the target market with specific preferences within a certain area or parameter. Other than social media location based marketing, advertising agencies or those with direct sms messaging marketing use data gathered from applications that determine location or use GPS, in order to collect data of consumers within a certain area to enable them to be targeted by sms advertisements, promotions and offers. Location based marketing is the process of an institution reaching out for the consumers in a certain targeted location with special promotions, offers, or demand creating advertisements that lead these consumers into purchasing goods or services from the institution depending on what it has to offer. Location based marketing has become a major stream of today's marketing and the main aspect of social media marketing, with a tendency of its usage to grow till it becomes a necessity to a huge chunk of companies and organizations. In other words, location based marketing is the today and future of marketing.

Location Based Marketing has enabled the interaction between businesses and customers and has made the relationship between these two sides on a much personal and direct level, therefore leading to an increase on the usage of Location Based Marketing techniques by both businesses and customers due to the important aspects in which LBM contains which have made it 
in most cases much more satisfactory as a return on investment for businesses and as a shopping experience for customers.

\section{Location Based Marketing Applied}

Location Based Marketing are the marketing tactics based upon the consumer's geographical location. These tactics take into consideration data collected about and from consumers. Location Based Marketing or LBM, is any form of marketing that uses location data in order to have the upper hand, or better odds in delivering the message to the customer at the right time and place. (Chamberlain, 2017) Where the marketing department looking to adapt LBM must primarily collect location data surrounding the potential market and target market, which this data is not only the location factor of these customers but may also include several other factors. Consumer's trust in technology is what has led to giving location based marketing an upper hand, hence the more the consumer trusts in technology the more personal data he enters into this technology leading to more data being available to the organizations which in return uses that data to target the consumer. Location Based Marketing tactics may include online and offline targeting methods. These methods aim to design specific targeted advertisements that reach out to consumers with the goal of turning them into possible customers. ( Miller, 2019) This is where the role of the marketing team is to develop the marketing campaign or advertisement which would lead to having the targeted potential customer convinced therefore creating demand on the product or service being marketed.

The term often used to define location based marketing is "Geomarketing". ( Miller, 2019) Geo, referring to the word geography resembling the geographical location of the customer in which location based comes from, and marketing. The main aim of location based marketing may be summarized by the phrase "getting your business in front of customers when they are most interested in purchasing your product or service. (Hendricks, 2017) This is precisely what the process of location based marketing is about, because by achieving this process, it is more likely to have the customer go through with the purchase of the product or service, therefore achieving what any marketing strategy aims for. A customer walking into a shopping area, is a potential customer, and once he is already present in that area, it means this is the right place and time to target that customer because they are most likely present to browse or shop, and so delivering the precise message needed could turn into the precise purchase trigger.

\section{Business Approaches Towards Customers in Location Based Marketing}

Location based marketing does not only depend or rely on having the customer being present or near a specific area. The organization, store, or company can be far off, yet set a designated potential market area in order to target. This process is achieved through online tactics. The preferences data collected through several forms or provided by numerous platforms grant access to the marketing teams in order to target these potential customers. This option is mostly present on social media platforms. For example, if a potential consumer is browsing along his newsfeed on Facebook, a 50\% sale advertisement on Sketchers running shoes would with no doubt grab his attention, and possibly cause him to want to grab the chance to order his running shoes online from the provided link without even having to have moved to the store to check up the promotions and make the purchase. (Munoz, 2019)

Location Based Marketing data gathering can play an essential role in shaping up the location target to a certain area by marketers or by a specific company. The data gathered is essential in analyzing popularity and demand of the company's product or brand in a certain area. This company could use this data intelligence to analyze and interpret the attribution and orders upon their product in the specified area. The area may be a street, a town, a city, a state, or even a country. This knowledge would help shape up the company's marketing strategy within that 
location, extending to building up the company's international marketing campaign alongside the company's internationalization techniques. (Munoz, 2019)

The usage of location based marketing a method for marketing campaigns is increasing rapidly. This method shall continue to flourish and prosper as it is already considered an essential present and futuristic technique. Main elements leading to this continued increase of usage is are the technological advancements which include the advancement of location data gathering means, and the evolution of location targeting mechanisms; where both businesses and customers shall demand and perhaps need this method which they will find preferable which makes it easier to address the customer in the right way, time, and place, and enables the customer to conduct the required purchase in an easier procedure. (Munoz, 2019)

\section{Conclusion}

Location has long played an essential role in shaping up marketing especially with respect to determining the methods and strategy set for targeting and segmentation taking place by any marketer when tackling certain target markets and certain customers. Location Based Marketing is the marketing method which builds upon the location aspects and location information gathered to deliver that right targeted and segmented marketing criteria at the right time and place, and over time the technological advancement is leading to further advancement and depending on location based marketing, during the Covid-19 pandemic, most countries were on lockdown for months causing customers to stay home, and businesses to shut down their doors, which meant businesses had to target customers at their own home and reach out for them in order to have them make a purchase, and customers themselves tended to location based marketing methods in order to be able to shop or get the products they demand, this issue during the pandemic has made much business and customers alike realize how much of an advantage location based marketing has become, and the increase in the usage of this method is not expected to drop even after the pandemic.

\section{References}

1. Act On. (2017). Geodemographics: Using Location-Based Segments for Targeted Marketing. Act On Blog. Available from:https://www.act-on.com/blog/geodemographics-targetedmarketing/ [Accessed 10/02/2020]. (INTERNET SOURCE)

2. Chamberlian, L. (2017). "Geomarketing 101: What Is Geomarketing? GeoMarketing by Yext/ Available from: geomarketing.com/geomarketing-101-what-is-geomarketing [Accessed 15/03/2020] (INTERNET SOURCE)

3. Hendricks, B. (2018). What is Geomarketing? - Definition, Tools \& Analysis. Study.com. Available from: https://study.com/academy/lesson/what-is-geomarketing-definition-toolsanalysis.html [Accessed 18/12/2019]. (INTERNET SOURCE)

4. Miller, D. (2019). What is Location-Based Marketing?. The Balances. Available from: https://www.thebalancesmb.com/what-is-location-based-marketing-4172454 [Accessed 12/12/2019]. (INTERNET SOURCE)

5. Munoz, A. (2019). 'Geomarketing \& Intelligence: The spy who loves you.' Sales Layer (February 2019). Available from: https://blog.saleslayer.com/geomarketing-locationintelligence-the-spy-who-loves-you [Accessed 05/04/2019]. (ONLINE JOURNAL ARTICLE) 